\title{
A new tool for assessment and monitoring of community and ecosystem change based on multivariate abundance data integration from different taxonomic groups
}

\author{
Melanie Mueller, Joachim Pander and Juergen Geist
}

\begin{abstract}
Background: The integrative assessment of responses to environmental disturbance simultaneously considering multiple taxonomic groups or guilds has become increasingly important in ecological monitoring. The most common solution to combine data of different taxonomic groups is the calculation of compound indices comprising several individual indicators. However, these indices run the risk of cancelling out underlying trends when single components change in different directions. In contrast, multivariate community analyses are supposed to be more sensitive to detect environmental responses, since information on the abundance of multiple species is not reduced to a single dimension.
\end{abstract}

Results: We propose a new standardised approach for multivariate community analyses on ecosystem scale, based on a combined data matrix from different taxonomic groups. The power of these multivariate analyses is compared with two single score indices integrating data from all involved taxonomic groups (Ecological Quality Class according to the European Water Framework Directive and Shannon diversity). The multivariate indication of ecosystem change was much more sensitive and powerful in detecting and monitoring environmental impacts and restoration effects than single numeric score indices.

Conclusions: Compared to common monitoring systems based on compound indices, the multivariate analysis of multiple taxonomic groups is feasible with the same sampling effort, and independent of the investigation scale and the occurrence of certain indicator taxa. Since ecological community data are structured similarly throughout freshwater, marine and terrestrial ecosystems, the presented methods for data combination and multivariate indication can be analogously applied in any other habitats and can improve data integration across ecosystem borders.

Keywords: Water quality; Environmental impact assessment; Habitat monitoring; Community ecology; Freshwater biodiversity; Fishes; Periphyton; Macrophytes; Macroinvertebrates

\section{Background}

In the context of increasing degradation of natural resources, knowledge on the current status and future change of ecosystems and habitats is crucial to maintain the services they provide (Millennium Ecosystem Assessment 2005). Twenty years ago, the United Nations proclaimed the "ecosystem approach" as the primary framework of the

\footnotetext{
* Correspondence: geist@wzw.tum.de

Aquatic Systems Biology Unit, Department of Ecology and Ecosystem Management, Technische Universität München, Mühlenweg 22, Freising D-85350, Germany
}

Convention on Biological Diversity (CBD; United Nations 1992), which proposed a holistic way to assess and manage ecosystems considering all plant, animal and bacterial communities and their non-living environment. From 1992 onwards, the objectives of the CBD have been gradually incorporated into international environmental legislation, considering the "ecosystem approach" by declaring the inclusion of multiple taxonomic groups into environmental monitoring mandatory (e.g. Republica de Panama 1998; European Parliament 2000; Republica Argentina 2002; Republic of Namibia 2004). Consequently, there is

\section{穴}


an increasing need to be able to evaluate change across multiple taxonomic groups when considering overall ecosystem state. However, nearly all current monitoring methods are index-based and have deficiencies and shortcomings, mainly because only specific groups of organisms are considered, or ecological assessment is based and dependent on the presence of indicator taxa. The European Water Framework Directive (WFD) is also based on indicator taxa, but provides a rare example of environmental regulation that gives concrete instructions on how data from different taxonomic groups should be integrated. The index-based WFD data analysis concept, similar to other multi-metric indices of biotic integrity (IBIs, first published for the assessment of fish communities by Karr 1981; e.g. Barbour et al. 1999; Birk et al. 2012; Vackar et al. 2012; Wilson and Bayley 2012) or diversity indices, is based on the general assumption that all considered metrics and taxonomic groups have to be fitted into single numeric scores. However, the strong reduction in information content makes this approach prone to levelling out valuable information in the final overall assessment (e.g. if two groups react in an opposite way) and can lead to erroneous conclusions about the real ecological status (Reynoldson et al. 1997; Millenium Ecosystem Assessment 2005; Caroni et al. 2013). Caroni et al. (2013) recently proposed that keeping all the information supplied by different taxonomic groups would produce a better overview of the entire ecosystem than calculating single score indices, but did not suggest a precise solution for data analysis and the presentation of the results. In the few scientific studies in which several taxonomic groups are considered, ecological community analyses are typically run separately for each group (e.g. Heino 2001; Paavola et al. 2006; Johnson et al. 2006). The outcome of such complex multi-group studies is likely to be an assemblage of numerous results plots from multivariate or univariate statistics (e.g. Heino et al. 2005; O'Connor et al. 2000) and it remains difficult to get a holistic and at the same time clear picture of the ecosystem as a whole. Despite of the availability of multivariate methods that allow for the simultaneous inclusion of a large number of variables without reducing information to single numeric scores (e.g. multidimensional scaling, principle components analysis, correspondence analysis) which all proofed to be very effective in the analysis of single taxonomic groups in the past (Reynoldson et al. 1997; Mueller et al. 2011; RIVPACS-like macroinvertebrate evaluation systems: Wright et al. 2000; Smith et al. 1999), these techniques are currently not applied to combine species abundance data from several levels of biological organisation within one analysis. This may be due to difficulties in combining species abundance data from taxonomic groups that require different sampling methods and investigation scales, resulting in different data structure. Consequently, the integration of multiple taxonomic groups needs standardized and statistically appropriate combination rules. The necessity for applying more standardized procedures which integrate community and ecosystem changes over multiple taxonomic groups and guilds has been proposed for assessment of freshwater ecosystem functioning (Geist 2011) as well as for aquatic restoration (Pander and Geist 2013), but may also be useful for any other ecosystem type.

The aim of this study was to develop a standardised procedure for monitoring ecosystem and community change by generating a combined data matrix based on species abundance data from different taxonomic groups, and to validate this approach using three typical data sets from freshwater ecosystems. Specifically, we propose and validate that (I) the generation of a combined species abundance data matrix from multiple taxonomic groups based on different sampling techniques and investigation scales is possible if standardisation/normalisation procedures which account for differences in species numbers and numerical scale are appropriately considered. (II) The integrative consideration of multiple taxonomic groups into multivariate community response analysis does not reduce the capability of detecting environmental gradients and differences between treatments compared to single taxonomic groups. (III) Combining information from multiple taxonomic groups using multivariate analysis is advantageous for the quantification of environmental changes compared to univariate (i.e. Shannon Index) or descriptive (i.e. WFD Ecological Quality Class) analyses of single compound indices. Compared to current methods, the herein proposed standardized procedure for analysing community and ecosystem change considers a combined data matrix based on normalized or averaged abundance data, derived from different sampling strategies, being independent of the scale of investigation and the presence of indicator taxa.

\section{Methods}

\section{Data sets}

All analyses were carried out exemplarily for three large data sets from freshwater ecosystems focused on the monitoring of environmental impacts and restoration success. Each data set includes the taxonomic groups periphyton, macroinvertebrates, macrophytes and fishes. Data structure was partially different between taxonomic groups and data sets concerning quantitative or semiquantitative data, sampling methods, as well as number of sampled river stretches and treatments. Data set (1) was focused on a pairwise comparison of upstream and downstream sides of weirs in five different rivers (Mueller et al. 2011; periphyton: scraping from stones and sedimentation method, macrophytes: point abundance sampling with garden rake, 
macroinvertebrates: surber sampling, fishes: electrofishing), data set (2) was collected from lotic and lentic freshwater habitat types (river, oxbow, drainage ditch) before and after floodplain restoration at the German section of the Danube River (Stammel et al. 2012; periphyton: scraping from stones and sedimentation method, macrophytes: point abundance sampling with garden rake, macroinvertebrates: kick sampling, fishes: electrofishing) and data set (3) is focused on the effects of four substratum restoration treatments (substratum raking, two different types of gravel introduction, sickle-formed current constrictor) in three calciferous and three silicious rivers distributed throughout the German federal state Bavaria (Mueller et al. 2014; Pander et al. 2014; periphyton: scraping from stones and sedimentation method, macrophytes: visual plot assessment, macroinvertebrates: surber sampling, fishes: electrofishing). Details on the sampling methods, sampling design, sample numbers and numbers of species and individuals per data set are presented in Mueller et al. (2013). For data sets 2 and 3 one additional sampling period (one year after restoration) applying the same sampling design as described in Mueller et al. (2013) was included in this study.

\section{Methods for merging raw data}

Three principal different methods for combining species abundance data from different taxonomic groups were applied (Figure 1) and compared by multivariate Spearman rank correlations and $2^{\text {nd }}$ Stage NMDS of the resulting resemblance matrices (based on Bray-Curtis Similarity) in Primer v6 (Clarke and Gorley 2006). This procedure is commonly used to compare multivariate community patterns derived from different taxonomic groups, data transformations or taxonomic levels and was first published by Somerfield and Clarke (1995).

As first and most simple method, raw species abundance data matrices were combined by inserting the species of each group as additional columns (Figure 1). This method is referred to as "untreated" in the following text. "Untreated" data were used as reference to analyse effects of differences in species numbers and numerical scale between taxonomic groups.

Secondly, data of periphyton, macrophytes, macroinvertebrates and fishes were normalized prior to the combination of data matrices by dividing each value by the sum of all abundance values throughout the matrix and multiplying with 1000 (Figure 1). The multiplication with the factor 1000 was applied to avoid very small numbers and to enhance legibility. The division by the sum of the matrix was used for normalization, i.e. to ensure that each taxonomic group had the same weighting in the subsequent analyses without losing quantitative information (which would happen by applying relative abundances, i.e. the sum of each row). The respective $R$ script for automatic matrix normalisation and combination is provided in the online supporting information (Additional file 1). This method is referred to as "normalized" in the following text.

Thirdly, resemblance matrices were calculated separately for each taxonomic group based on Bray-Curtis Similarity in Primer v6, and averaged in Microsoft ${ }^{\circ}$ Excel (Figure 1). The resulting overall resemblance matrix was also expected to contain the same weighting for each group. This method is called "averaged" in the following text and the averaged resemblance matrix was re-imported in Primer v6 to be compared in $2^{\text {nd }}$ Stage NMDS analysis with resemblance matrices from untreated and normalized data as well as the resemblance matrices of single taxonomic groups.

\section{Evaluation of the statistical performance of combined data}

PERMANOVA (permutational MANOVA; Anderson et al. 2008) in Primer v6 (Plymouth Marine Laboratory, Plymouth, UK) was used to analyse differences between treatments (i.e. sampling time points and restoration treatments in data sets 2 and 3). PERMANOVA is a routine for testing the multivariate response to one or more factors on the basis of any resemblance measure. It computes Pseudo-F values (the larger the F value, the more likely the null hypothesis of no differences among the group means is false; Anderson 2001) and permutational p-values, which were used to compare the discriminatory power of "overall abundance data" and single taxonomic groups. To evaluate the capability to detect community responses to environmental gradients of "overall abundance data", BEST BV-STEP analyses were carried out in Primer v6 for combined data and for single taxonomic groups. The BEST-procedure performs a stepwise search and Spearman rank correlation to find a minimum combination of environmental variables which results in maximum possible correlation with the biotic data. Following Olsgard et al. (1997), the strength of Spearman rank correlation was used to evaluate the goodness of description of community patterns resolved from different resemblance matrices (overall, periphyton, macrophytes, macroinvertebrates, fishes).

\section{Comparison of multivariate indicators and single numeric score indices}

To compare the sensitivity of multivariate analysis on the overall data matrix and integrative single score indices, the ecological status according to the WFD and overall Shannon diversity (Shannon 1948) were calculated. The ecological status was determined applying the European/German evaluation systems for the biological quality elements fishes (European fish index EFI; Pont et al. 2007), macroinvertebrates (PERLODES; AQEM Consortium 2002) as well as diatoms, phytobenthos and 
Figure 1 Schematic of three different combination methods for raw species abundance data: "Untreated", "Normalized" and "Averaged". Data sets from different taxonomic groups are indicated as coloured squares: blue square $=$ taxa abundance data from taxonomic group 1 (e.g. fishes), green square = taxa abundance data from taxonomic group 2 (e.g. periphyton), yellow square = taxa abundance data from taxonomic group 3 (e.g. macrophytes), red square = taxa abundance data from taxonomic group 4 (e.g. macroinvertebrates). In each data set, samples (S) are rows and species/taxa (SP) columns; each cell in the data matrix contains an abundance value ( $x$, e.g. numbers of individuals, coverage, cell numbers or presence/absence). $B=$ Bray-Curtis Similarity, $\bar{x}=$ Normalized abundance, $\bar{B}=$ Averaged Bray-Curtis Similarity.

macrophytes (PhyLib; Schaumburg et al. 2012) using pooled data from all replicates from each treatment (upstream and downstream sides of weirs in data set 1 , preand post-restoration status in data sets 2 and 3). Pooled data were used to reach minimum abundances for index calculation and to fulfil the criteria of the multihabitat sampling technique of the WFD protocols. Since the calculation method for combining the results from the different biological quality elements can have a major impact on the results, we applied two different combination methods. First, the currently practiced "one-out-all-out" combination rule was used, where the overall Ecological Quality Class is determined by the biological quality element with the lowest value. Second, the arithmetic mean of the index values from all biological quality elements (periphyton (including diatoms and remaining phytobenthos), macrophytes, macroinvertebrates, fishes) was calculated. Additionally, overall Shannon diversity was calculated as further single score index from the normalized overall abundance data (integrating periphyton, macrophytes, macroinvertebrates and fishes) using the DIVERSE procedure in PRIMER v6. Ecological status scores where compared descriptively between treatments and the overall Shannon Indices were analysed by univariate statistics (Mann-Whitney-U test since all data were not normally distributed). Results from the two single numeric score indices were compared with those from multivariate analysis of overall community composition (Bray-Curtis Similiarity and PERMANOVA p-values).

\section{Results}

The ecosystem level multivariate community pattern derived from the method "untreated" was strongly dominated by one of the four taxonomic groups in all three data sets (Figure 2). Mostly, the numerically dominant group in terms of individuals and species was periphyton. Only in data set 1 , where periphyton data structure was different (presence-absence data), the "untreated" pattern was dominated by the macroinvertebrates. The contribution of single taxonomic groups to the overall community pattern ranged from 0.07 to 1.00 for the method "untreated" $(0.43 \pm 0.34)$ and was more evenly distributed between taxonomic groups for the methods "averaged" 


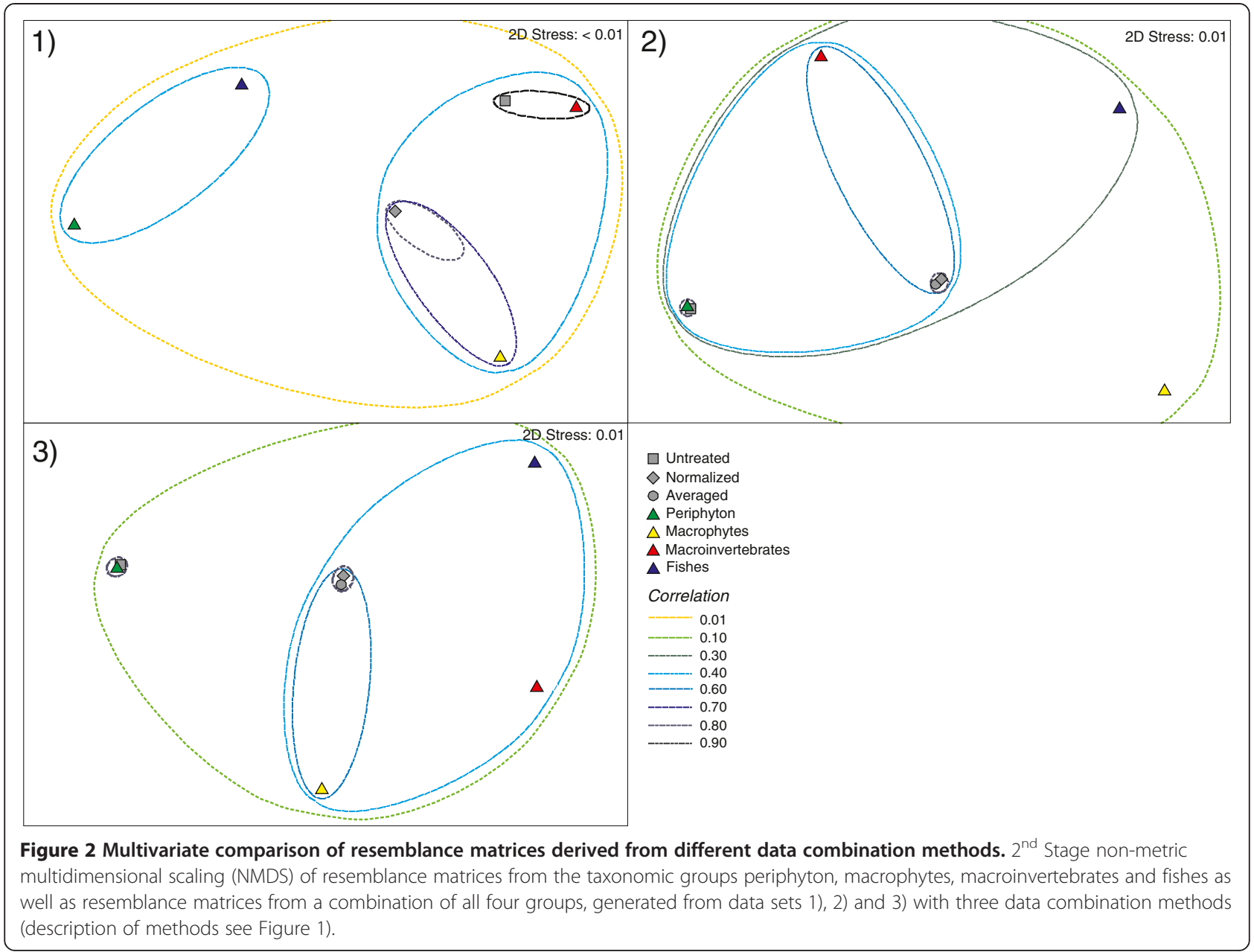

( range $=0.18-0.86 ;$ mean $=0.59 \pm 0.16)$ and "normalized" (range $=0.29-0.69 ;$ mean $=0.57 \pm 0.11$ ). The results from the methods "averaged" and "normalized" were similar to each other, with a mean Spearman rank correlation coefficient of $0.90(\mathrm{SD}=0.01$, Figure 2).

PERMANOVA main tests revealed intermediate Pseudo$F$ values for combined data (data set 2: Pseudo-F (restoration treatments and time points) $=6.08$, Pseudo-F (habitats) $=5.27$; data set 3: Pseudo-F (restoration treatments and time points) $=2.41$, Pseudo-F (habitats) $=12.35$ ) compared to single taxonomic groups (data set 2: Pseudo-F (restoration treatments and time points) $=1.87-7.73$, Pseudo-F (habitats) $=2.50-15.75$; data set 3 : Pseudo-F (restoration treatments and time points) $=0.96-6.52$, Pseudo$F$ (habitats) $=6.52-19.79$ ). No differences were detected between $\mathrm{p}$-values from PERMANOVA main tests on combined data and single taxonomic groups $(\mathrm{p}=0.001)$, except for macrophytes in data set 3 , where $p$-values were much higher and indicated no significance $(\mathrm{p}=0.53)$. Test results for single habitats within the data sets also differed among taxonomic groups. The subset of habitats with a significant difference in community composition revealed by analysis of combined data represented a synthesis of the results from single taxonomic groups. However, for the analysis of single taxonomic groups, several samples had to be excluded from fishes in data set 2 and macrophytes in data set 3 due to all-zero-values, limiting statistical power. Only for combined data all samples could be integrated into the analyses for each data set.

BEST analyses revealed highest correlation with environmental variables for macrophytes $(\rho=0.67 \pm 0.16)$, fishes $(\rho=0.61 \pm 0.08)$ and combined data ( $\rho$ "normalized" = $0.60 \pm 0.04)$. Lowest correlation occurred for periphyton $(\rho=0.42 \pm 0.21)$. The number of included variables ranged between 1 and 6 for single taxonomic groups and between 1 and 3 for combined data ("normalized").

Shannon diversity of combined data did not significantly differ between habitats or restoration treatments for data sets 2 and 3, while multivariate analyses indicated a significant change of overall community composition after restoration in river $(\mathrm{R})$ and oxbow $(\mathrm{O})$ habitats of data set 1 and 3 of 6 study rivers from data set 2 (Table 1). In data set 1, univariate statistics revealed significant differences in Shannon diversity between upstream and downstream 
Table 1 Comparison of multivariate analysis using multi-group abundance taxa with Shannon diversity and Ecological Quality Class

\begin{tabular}{|c|c|c|c|c|c|c|c|}
\hline Data set & River/Habitat & Bray-Curtis & p PERMANOVA & $\Delta$ Shannon & p U-test & $\Delta \mathrm{EQC}$ & $\Delta$ EQC (av) \\
\hline \multirow[t]{5}{*}{1} & W & 61 & $<0.01$ & 0.25 & $<0.05$ & 1 & 0 \\
\hline & S & 48 & $<0.01$ & 0.31 & $<0.01$ & 1 & 1 \\
\hline & M & 47 & $<0.01$ & -0.04 & $>0.05$ & 1 & 0 \\
\hline & $L$ & 74 & $<0.05$ & -0.11 & $>0.05$ & -1 & 0 \\
\hline & G & 48 & $<0.01$ & 0.80 & $<0.001$ & 0 & 0 \\
\hline \multirow[t]{3}{*}{2} & $\mathrm{R}$ & 29 & $<0.001$ & 0.32 & $>0.05$ & 0 & 0 \\
\hline & O & 33 & $<0.001$ & 0.13 & $>0.05$ & 0 & 1 \\
\hline & $\mathrm{D}$ & 31 & $>0.05$ & -0.16 & $>0.05$ & 0 & 0 \\
\hline \multirow[t]{6}{*}{3} & $A G$ & 34 & $<0.01$ & -0.40 & $>0.05$ & 2 & 2 \\
\hline & $\mathrm{GO}$ & 61 & $<0.05$ & 0.01 & $>0.05$ & 0 & 1 \\
\hline & MG & 50 & $>0.05$ & 0.31 & $>0.05$ & -1 & 0 \\
\hline & $P$ & 67 & $>0.05$ & 0.17 & $>0.05$ & -1 & 0 \\
\hline & $S R$ & 28 & $<0.05$ & 0.07 & $>0.05$ & 0 & 0 \\
\hline & W & 79 & $>0.05$ & 0.14 & $>0.05$ & 0 & 0 \\
\hline
\end{tabular}

River/Habitat = Codes for the studied rivers/habitats; Bray-Curtis = Bray-Curtis Similarity between treatments; $p$ PERMANOVA = $\mathrm{p}$-values derived from PERMANOVA analysis between treatments; $\triangle$ Shannon = difference in Shannon diversity between treatments, $p U$-test $=p$-value derived from Mann-Whitney-U test between treatments; $\triangle \mathrm{EQC}=$ difference in Ecological Quality Class according to Water Framework Directive, calculated following "one-out-all-out" combination rule; $\Delta \mathrm{EQC}$ (av) = difference in Ecological Quality Class according to Water Framework Directive, calculated by averaging EQC values from diatoms, phytobenthos, macrophytes, macroinvertebrates and fishes. Abbreviations of river names in data set 1: W = Wiesent, $S=$ Sächsische Saale, $M=M o o s a c h, L=$ Leitzach, $G=G u ̈ n z ;$ abbreviations of habitats in data set 2: $R=$ river stretches, $O=$ oxbow stretches, $D=$ drainage ditch; abrreviations of river names in data set 3: $A G=A$ lte $G u ̈ n z, G O=G r o ß e$ Ohe, MG = Mühlangergraben, $\mathrm{P}=$ Perlenbach, $\mathrm{SR}=$ Südliche Regnitz, $\mathrm{W}=$ Wiesent.

sides of weirs in three of five rivers, while multivariate analysis of combined species abundance data could detect weir effects on overall community composition for all study rivers at different levels of significance (Table 1). The ecological quality class (EQC) values could not be analysed with statistics due to the need for pooling data over all replicates to reach minimum abundances for index calculation. The descriptive comparison of EQC values between treatments generally had a lower sensitivity to detect differences in the overall community than multivariate community analysis (Table 1). Multivariate analyses also allowed a finer graduation of effect size than EQC values. Furthermore, the resulting EQC was strongly dependent on the method of combining the indices from single taxonomic groups. The calculation according to the "one-out-all-out" rule of the WFD evaluation system revealed more differences in EQC between treatments than averaged values of the multi-metric indices from single taxonomic groups. However, the results from both calculation methods often were not in line with those from multivariate community analysis and univariate analyses of single parameters (e.g. productivity, species richness, Shannon diversity). For instance, $\mathrm{R}$ and $\mathrm{O}$ habitats of data set 2 showed a highly significant change in overall community composition after restoration, while the EQC value did not change. The rivers $\mathrm{P}$ and $\mathrm{MG}$ of data set 3 did not change according to PERMANOVA analysis and univariate analysis of Shannon diversity, while the EQC value even indicated degradation after restoration. However, single parameter analysis indicated a slightly increased productivity and species richness, which is generally not considered as degradation. For the detection of weir effects (data set 1 ) the "one-out-all-out" calculated EQC was reliable, but did not allow a differentiation of effect size which is possible in multivariate analysis by comparing Bray-Curtis Smiliarties and PERMANOVA p-values.

\section{Discussion}

This study presents and evaluates standardized methods for the implementation of simultaneous multivariate analyses of community structure integrating multiple taxonomic groups, applying Bray-Curtis Similarity and NMDS. Since ecological community data usually are available as 'species' $x$ 'sites' matrices, with a type of abundance in each cell, independent of habitat type and ecosystems, the presented methods for data combination may be universally applied to integratively assess community change in multiple taxonomic groups. The main advantage of this multivariate approach is the high sensitivity to stressors at multiple scales and the universal applicability across ecosystem borders and geographic regions.

\section{Representativeness of different methods for merging data sets}

The methods "normalized" and "averaged" were similarly suitable to produce a representative overall community 
pattern with a balanced contribution of each taxonomic group. As expected, the simple combination of "untreated" data cannot be recommended, since the outcome is strongly dominated by the taxonomic group with highest numbers of species and individuals. For instance, in central European rivers, algal species richness and cell numbers are usually much higher than numbers of fish species and individuals, as also evident in data sets 2 and 3. Compared to the use of percent-abundance data, which would result in a sum of $100 \%$ for each study site, the "normalizing" and "averaging" methods suggested herein preserve differences in total abundance between sites. Since the total number of individuals per site is an important proxy for ecosystem productivity (Karr 1981; Oberdorff et al. 2002), it can be of great relevance not to lose this information in environmental impact assessments (Mueller et al. 2011). Since presence-absence data (e.g. periphyton in data set 1), percent-abundance data (e.g. macrophytes in data set 3 ) and quantitative data (fishes and macroinvertebrates in all data sets) generated using strongly different sampling methodology (e.g. electrofishing, surber sampling, estimation of coverage) had similar contributions to the overall picture after standardisation by "averaging" and "normalizing", these methods can be performed irrespective of data structure and sampling method, provided that all matrices include the same set of study sites. This can be advantageous if heterogenous data structures arising from different research fields, such as vegetation science (plant coverage is described as frequency of occurrence on a predefined scale) and zoology (single individuals are counted), have to be combined in large monitoring programs. The major disadvantage of the "averaging" method is that sites where one of the taxonomic groups is absent cannot be included in the analyses due to undefined similarity values for all-zero-samples. Since data from different taxonomic groups are combined in the form of abundance data prior to the calculation of resemblances in the procedure of "normalizing", all-zero-samples for single taxonomic groups do not have to be excluded provided that individuals of any other taxonomic group occurred in the sample. The normalized multi-group abundance data can also be used for the calculation of other similarity measures and multivariate statistics than those applied herein.

\section{Comparison of multivariate indicators and single numeric score indices}

The power of PERMANOVA and BEST to distinguish between treatments was not reduced for combined data and the results were reasonable compared to single taxonomic groups, indicating that the multivariate consideration mirrored restoration-induced changes in aquatic communities and the most important physicochemical drivers. In general, the significance level provided by multivariate statistics allowed a very subtle quantification of effect size independent of the spatial scale of the data set (Table 1). In contrast, index-based ecological indicators are likely to be more suitable for the detection of broad-scale trends of change or major impacts (e.g. differences between upstream and downstream sides of weirs in data set 1) than for the detection of local scale stressors (Dahm et al. 2013) or habitat change (e.g. effects of restoration measures in data sets 2 and 3; Jähnig et al. 2011). The major advantage of multivariate methods is that the information content is not reduced to a single numerical score, which is more prone to levelling out adverse effects of single taxonomic groups. For instance, in data set 3 , a strong decrease in macrophyte diversity disguised the restoration-induced increase in macroinvertebrate diversity in univariate analyses, making the EQC and overall Shannon index less sensitive or even misleading indicators compared to multivariate overall community patterns. The WFD evaluation system and similar indices strongly depend on the presence of distinct indicator taxa at minimum abundances from each group included, which reduces their applicability in ecosystems with high anthropogenic pressure and dominance of neobiota (Arndt et al. 2009). This was evident in all of the studied data sets, resulting in uncertain values or even impossible index calculation for single taxonomic groups in many rivers although up to 25 replicate samples were pooled. Multivariate community analysis of overall data sets is independent of indicator taxa and minimum abundances and can be carried out with any set of species that may occur using the full number of replicates. Characteristic species for certain habitats can be determined case specific and comprehensively within one analysis for all taxonomic groups, using e.g. SIMPER (Clarke and Gorley 2006) or TITAN (Baker and King 2010) analyses. This procedure can be applied across ecosystem types. Measures of productivity (e.g. biomass, numbers of individuals, length-frequency distributions) can be better accounted for in multivariate community analyses than in the WFD evaluation system, which for instance only allows a differentiation of fishes smaller and larger than $15 \mathrm{~cm}$ and delivers the same EQC value for a site with $5 \mathrm{in}$ dividuals of the same species as for a site with 500 individuals. A further limitation of the multi-metric index system used in the WFD evaluation is its dependence on reference conditions, which are mostly based on expert estimation and are often hampered by knowledge gaps. Moreover, reference conditions are missing for many habitat types, such as for oxbows, lakes or artificial fish bypass channels (which differ in discharge and size from the main river) in aquatic ecosystems. Multivariate analyses can be applied more flexible, e.g. for relative comparisons between different habitats or for comparisons between treated sites and untreated reference sites that could be considered as "reference to move away from" (Palmer et al. 2005). If existing reference conditions of single taxonomic groups were combined, the 
species abundance data combination and normalisation method proposed herein could also provide the basis to extend well established multivariate evaluation tools from their current application for single taxonomic groups (e.g. RIVPACS: Wright et al. 2000; AUSRIVAS: Smith et al. 1999; BEAST: Rosenberg et al. 1999 for river macroinvertebrates) to more holistic models integrating several levels of biological organisation.

\section{Conclusions}

The combination of "normalized" taxa abundance data from multiple taxonomic groups proofed to be an easy and representative method for the three validation data sets from freshwater ecosystems. This is a prerequisite for statistically verifiable multivariate indication of ecosystem change. Compared to common monitoring systems based on multimetric indices, the multivariate analysis of multiple taxonomic groups presented herein, based on current statistical methods, is feasible with the same sampling effort but constitutes a much more sensitive indicator. This approach can also be applied for taxonomic surrogates (e.g. coarser taxonomic levels, functional guilds, Mueller et al. 2013) and can be performed independent of ecosystem type, sampling strategy and the occurrence of certain species. Existing global indices in aquatic systems (e.g. Water Framework Directive, Rapid Bioassessment) are restricted to certain ecoregions and tend to be insensitive to local scale stressors. In contrast, the methods proposed herein may be universally applied at multiple scales. The presented multivariate approach can help to improve data integration across borders of adjacent habitats and ecosystems that are exposed to similar stressors (e.g. alterations of groundwater level in aquatic and terrestrial floodplain habitats), thus allowing comparisons of effect size between ecosystem types. The $\mathrm{R}$ script for automatic matrix normalization and combination provided herein can be a useful tool for future ecosystem monitoring in freshwater, marine and terrestrial systems.

\section{Additional file}

Additional file 1: R script for matrix normalization.

\section{Competing interests}

The authors declare that they have no competing interests.

\section{Authors' contributions}

MM participated in field sampling, conducted the taxonomic identification of sampled specimens, designed the multivariate statistical approach of the study, and drafted the manuscript. JP coordinated the field sampling and helped with the taxonomic identification. JG validated the statistical approach and secured funding for the project. MM, JP and JG jointly discussed and interpreted the results, wrote and approved the manuscript.

\section{Acknowledgements}

We are especially grateful to Dipl. Ing. Martin Knopp for his contribution in computing the R script. We acknowledge support to MM by the TUM Graduate School and a doctoral scholarship of UniBayern e.V.. This work was supported by the German Research Foundation (DFG) and the Technische Universität München within the funding programme Open Access Publishing.

Received: 28 January 2014 Accepted: 24 March 2014

Published: 8 April 2014

\section{References}

Anderson MJ (2001) A new method for non-parametric multivariate analysis of variance. Austral Ecol 26(1):32-46

Anderson MJ, Gorley RN, Clarke KR (2008) PERMANOVA + for PRIMER: Guide to Software and Statistical Methods. PRIMER-E Ltd, Plymouth

AQEM Consortium (2002) Manual for the application of the AQEM system. A comprehensive method to assess European streams using benthic macroinvertebrates, developed for the purpose of the Water Framework Directive. Available via DIALOG. http://www.aqem.de/ftp/aqem_manual.zip. Accessed 20 Mar 2014

Arndt E, Fiedler S, Böhme D (2009) Effects of invasive benthic macroinvertebrates on assessment methods of the EU Water Frame Work Directive. Hydrobiologia 635(1):309-320

Baker ME, King RS (2010) A new method for detecting and interpreting biodiversity and ecological community thresholds. Methods Ecol Evol 1(1):25-37

Barbour MT, Gerritsen J, Snyder BD, Stribling JB (1999) Rapid Bioassessment Protocols for Use in Streams and Wadeable Rivers: Periphyton, Benthic Macroinvertebrates and Fish. U.S. Environmental Protection Agency, Available via DIALOG. http://water.epa.gov/scitech/monitoring/rsl/bioassessment/. Accessed 20 Mar 2014

Birk S, Bonne W, Borja A, Brucet S, Courrat A, Poikane S, Solimini A, Van de Bund W, Zampoukas N, Hering D (2012) Three hundred ways to assess Europe's surface waters: An almost complete overview of biological methods to implement the Water Framework Directive. Ecol Indic 18:31-41

Caroni R, Van de Bund W, Clarke RT, Johnson RK (2013) Combination of multiple biological quality elements into waterbody assessment of surface waters. Hydrobiologia 704(1):437-451

Clarke RK, Gorley RN (2006) PRIMER v6: User Manual/Tutorial, 2nd edn. PRIMER-E Ltd, Plymouth

Dahm V, Hering D, Nemitz D, Graf W, Schmidt-Kloiber A, Leitner P, Melcher A, Feld C (2013) Effects of physico-chemistry, land use and hydromorphology on three riverine organism groups: a comparative analysis with monitoring data from Germany and Austria. Hydrobiologia 704(1):389-415

Geist J (2011) Integrative freshwater ecology and biodiversity conservation. Ecol Indic 11:1507-1516

Heino J (2001) Regional gradient analysis of freshwater biota: do similar biogeographic patterns exist among multiple taxonomic groups? J Biogeogr 28(1):69-76

Heino J, Paavola R, Virtanen R, Muotka T (2005) Searching for biodiversity indicators in running waters: do bryophytes, macroinvertebrates, and fish show congruent diversity patterns? Biodivers Conserv 14(2):415-428

Jähnig SC, Lorenz AW, Hering D, Antons C, Sundermann A, Jedicke E, Haase P (2011) River restoration success: a question of perception. Ecol Appl 21 (6):2007-2015

Johnson RK, Hering D, Furse MT, Clarke RT (2006) Detection of ecological change using multiple organism groups: metrics and uncertainty. Hydrobiologia 566 (1):115-137

Karr JR (1981) Assessment of biotic integrity using fish communities. Fisheries 6:21-27 Millennium Ecosystem Assessment (2005) Ecosystems and human well-being, synthesis. Island Press, Washington DC

Mueller M, Pander J, Geist J (2011) The effects of weirs on structural stream habitat and biological communities. J Appl Ecol 48(6):1450-1461

Mueller M, Pander J, Geist J (2013) Taxonomic sufficiency in freshwater ecosystems: effects of taxonomic resolution, functional traits and data transformation. Freshw Sci 32(3):762-778

Mueller M, Pander J, Geist J (2014) The ecological value of stream restoration measures: An evaluation on ecosystem and target species scales. Ecol Eng 62:129-139

O'Connor JR, Walls ET, Hughes RM (2000) Using multiple taxonomic groups to index the ecological conditions of lakes. Environ Monit Assess 61(2):207-228 
Oberdorff T, Pont D, Hugueny B, Porchers JP (2002) Development and validation of a fish-based index for the assessment of river health in France. Freshw Biol 47(9):1720-1734

Olsgard F, Somerfield PJ, Carr M (1997) Relationships between taxonomic resolution and data transformations in analyses of a macrobenthic community along an established pollution gradient. Mar Ecol Prog Ser 149 (1):173-181

Paavola R, Muotka T, Virtanen R, Heino J, Jackson D, Mäki-Petäys A (2006) Spatial scale affects community concordance among fishes, benthic macroinvertebrates, and bryophytes in streams. Ecol Appl 16(1):368-379

Palmer MA, Bernhardt ES, Allan JD, Lake PS, Alexander G, Brooks S, Carr J, Clayton S, Dahm CN, Follstad SJ, Galat DL, Loss SG, Goodwin P, Hart DD, Hassett B, Jenkinson R, Kondolf GM, Lave R, Meyer JL, O'Donnell TK, Pagano L, Sudduth E (2005) Standards for ecologically successful river restoration. J Appl Ecol 42 (2):208-217

Pander J, Geist J (2013) Ecological indicators for stream restoration success. Ecol Indic 30:106-118

Pander J, Mueller M, Geist J (2014) A comparison of four stream substratum restoration techniques concerning interstitial conditions and downstream effects. River Res Appl, doi: 10.1002/rra.2732

Parliament E (2000) Directive 2000/60/EC of the European Parliament and the Council establishing a framework for the Community action in the field of water policy. Official Journal of the European Union 327:1-73

Pont D, Hugueny B, Rogers C (2007) Development of a fish-based index for the assessment of river health in Europe: the European Fish Index. Fish Manag Ecol 14(6):427-439

Republic of Namibia (2004) Water Resources Management, 2004. Government Gazette of the Republic of Namibia 3357:1-67

Republica Argentinia (2002) Ley N²5.688: Regimen de gestion ambiental de aguas., Available via DIALOG. http://www.opds.gba.gov.ar/index.php/leyes/ver/243. Accessed 11 April 2014

Republica de Panama (1998) Ley 41: Ley general del ambiente. In: Ley 41: Ley general del ambiente. Available via DIALOG. http://www.lawyers-abogados. net/es/recursos/Panama/Ley-41-1998-Ley-General-Ambiente.htm. Accessed 20 Mar 2014

Reynoldson TB, Norris RH, Resh VH, Day KE, Rosenberg DM (1997) The Reference condition: a comparison of multimetric and multivariate approaches to assess water-quality impairment using benthic macroinvertebrates. J North Am Benthol Soc 16(4):833-852

Rosenberg DM, Reynoldson TB, Resh VH (1999) Establishing reference conditions in the Fraser River catchment. Environment Canada, British Columbia, Canada, Available via DIALOG. http://research.rem.sfu.ca/frap/9832.pdf. Accessed 20 Mar 2014

Schaumburg J, Schranz C, Stelzer D, Vogel A, Gutowski A (2012) Verfahrensanleitung für die ökologische Bewertung von Fließgewässern zur Umsetzung der EG-Wasserrahmenrichtlinie: Makrophyten und Phytobenthos. Bayerisches Landesamt für Umwelt, Available via DIALOG. http://www.lfu.bayern.de/wasser/gewaesserqualitaet_seen/phylib_deutsch/verfahrensanleitung/ doc/verfahrensanleitung_fg.pdf. Accessed 20 Mar 2014

Shannon CE (1948) The mathematical theory of communication. The Bell System Technical Journal 27:379-423

Smith MJ, Kay WR, Edward DHD, Papas PJ, Richardson KSJ, Simpson JC, Pinder AM, Cale DJ, Horwitz PHJ, Davis JA, Yung FH, Norris RH, Halse SA (1999) AusRivAS: using macroinvertebrates to assess ecological condition of rivers in Western Australia. Freshw Biol 41(2):269-282

Somerfield PJ, Clarke KR (1995) Taxonomic levels, in marine community studies, revisited. Mar Ecol Prog Ser 127(1):113-119

Stammel B, Cyffka B, Geist J, Müller M, Pander J, Blasch G, Fischer P, Gruppe A, Haas F, Kilg M, Lang P, Schopf R, Schwab A, Utschick H, Weißbrod M (2012) Floodplain restoration on the Upper Danube (Germany) by re-establishing water and sediment dynamics: a scientific monitoring as part of the implementation. River Systems 20(1-2):55-70

United Nations (1992) Convention on Biological Diversity (text with annexes). United Nations, Available via DIALOG. http://www.cbd.int/doc/legal/cbd-en. pdf. Accessed 20 Mar 2014

Vackar D, Ten Brink B, Loh J, Baillie JEM, Reyers B (2012) Review of multispecies indices for monitoring human impacts on biodiversity. Ecol Indic 17:58-67
Wilson MJ, Bayley S (2012) Use of single versus multiple biotic communities as indicators of biological integrity in northern prairie wetlands. Ecol Indic 20:187-195

Wright JF, Sutcliffe DW, Furse MT (2000) An introduction to RIVPACS. Assessing the biological quality of freshwaters: RIVPACS and other techniques, Freshwater Biological Association, Ambleside, Ambleside

doi:10.1186/2193-2697-3-12

Cite this article as: Mueller et al: A new tool for assessment and monitoring of community and ecosystem change based on multivariate abundance data integration from different taxonomic groups.

Environmental Systems Research 2014 3:12.

\section{Submit your manuscript to a SpringerOpen ${ }^{\odot}$ journal and benefit from:}

- Convenient online submission

- Rigorous peer review

- Immediate publication on acceptance

- Open access: articles freely available online

- High visibility within the field

- Retaining the copyright to your article

Submit your next manuscript at $>$ springeropen.com 